\title{
Walk-ability Evaluation of Pedestrian Facilities
}

\author{
Jooyoung $\mathrm{Kim}^{1}$ and Seungjae Lee ${ }^{2^{*}}$ \\ ${ }^{1}$ Integrated Urban Research Center, University of Seoul, South Korea \\ ${ }^{2 *}$ Department of Transportation Engineering, University of Seoul, South Korea \\ ${ }^{1}$ trafficplan@naver.com, ${ }^{2}$ sjlee@uos.ac.kr
}

\begin{abstract}
Major cities in Korea are giving increasingly attention on pedestrian facilities in order to enhance public transportation usage and pedestrian movements, and thus to develop toward sustainable transport systems. The need for proper measurement of walk-ability of street furniture for pedestrian is now a key policy requirement to be evaluated. A sophisticated tool to measure the walk-ability of pedestrian furniture in detailed scale is demanding. In particular, it is important to measure the walk-ability of the pedestrian furniture in terms of its interaction with pedestrian movements. In this paper, we have developed the pedestrian simulation model based on cellular automata techniques. This model has a flexibility to measure the effectiveness of pedestrian street furniture in terms of level of service index based on its interaction with pedestrian movements. We have experimented how to evaluate the walk-ability of different types of furniture, which can reduce the conflict pedestrian movements in some highly congested areas.
\end{abstract}

Keywords: Pedestrian facility, Street furniture, Cellular automata, Group moving, Diagonal

\section{Introduction}

Major cities in Korea are giving increasingly attention on pedestrian facilities in order to enhance public transportation usage and pedestrian movements, and thus to develop toward sustainable transport systems. The need for proper measurement of effectiveness of street furniture for pedestrian is now a key policy requirement to be evaluated. A sophisticated tool to measure the effectiveness of pedestrian furniture in detailed scale is demanding. In particular, it is important to measure the effectiveness of the pedestrian furniture in terms of its interaction with pedestrian movements. Transport planners are giving increasingly attention on pedestrian facilities in order to enhance public transportation usage, and thus to develop toward sustainable transport systems and pedestrian space. The need for proper measurement of effectiveness of pedestrian facilities is now a key policy requirement to be evaluated. However, a tool to measure the effectiveness of pedestrian facilities is not available. Generally, in order to design systematic and scientific pedestrian facilities and space, the simulation can deal with different forms of pedestrian's characters by pedestrian model is essential. In this paper, level of service for pedestrian used data analyzed by Current Population Survey from the DB built in Seoul for gait analysis. In this paper, we have developed the pedestrian simulation model based on cellular automata techniques. This model has a flexibility to measure the effectiveness of pedestrian street furniture in terms of level of service index based on its interaction with pedestrian movements. We have experimented how to evaluate the effectiveness of different types of furniture, which can reduce the conflict pedestrian movements in some highly congested areas. This study has simulated the pedestrian's pattern by the developed cellular automata model. The model is able to represent realistic characteristics such as a group moving behavior and a diagonal

Received (January 5, 2018), Review Result (February 13, 2017), Accepted (March 16, 2018) 
overtaking behavior. Specifically, more flexibility is given to the movement of pedestrians by developing the diagonal lane change module by comparison with the existing cellular automata model's lane change module of only either left or right overtaking. In addition, this study has simulated the effectiveness of the various street furniture layouts to investigate the relations between a location of street furniture and pedestrian's moving speeds.

This paper consists of four sections. Section 1 introduces the general organization of this paper. In Section 2, the developed CA model is introduced based on the existing models reviewed. In the Section 3, the characteristics of the pedestrians in the two types of sidewalk are presented. And scenarios of various furniture layout designs are evaluated by the CA model. In the Section 4, the main findings are discussed.

\section{Cellular Automata Pedestrian Model}

A cellular automaton (CA) is a discrete model studied in computability theory, mathematics, physics, complexity science, theoretical biology and microstructure modeling. It consists of a regular grid of cells, each in one of a finite number of states, such as "On" and "Off" (in contrast to a coupled map lattice). The grid can be in any finite number of dimensions. For each cell, a set of cells called its neighborhood (usually including the cell itself) is defined relative to the specified cell. Cellular Automata (CA) micro-simulation is an effective technique (Levy 1992; Adami 1998). CA has been used for modeling complex phenomena in various fields (Chopard and Droz 1998). CA has a principle of neighborhood rules of occupancy. Traditional simulation models apply equations rather than behavioral rules, but CA behavior-based cellular changes of state determine the emergent results. CA models for road traffic and pedestrian analysis had received a great deal of interest (Fukui and Ishibashi 1996; M. Muramatsu 1999; M.Fukui and Ishibashi 1999; Burstedde, Klauck et al., 2001; Tajima, Takimoto et al., 2001; Kirchner and Schadschneider 2002; Schadschneider, Kirchner et al., 2002; Matsukidaira and Nishinari 2003; Takimoto and Nagatani 2003; H. K. Lee 2004; Seungjae Lee 2008). The modeling and simulation method for traffic flow can be applied to pedestrian flow. (Bak 1996). CA traffic models have been shown to provide a good approximation of complex traffic flow patterns over a range of densities including the formation of shock waves in traffic jams.

In 2008 the paper of Measuring Effectiveness of Pedestrian Facilities Using a Pedestrian Simulation Model by Lee(2008), that has developed the pedestrian simulation model based on cellular automata(CA) techniques. The model has a flexibility to measure the effectiveness of pedestrian facilities in terms of level of service index based on its interaction with pedestrian movements. The study has experimented the model how to evaluate the effectiveness of different types of fence in a subway station, which can reduce the conflict pedestrian movements in some highly congested areas.

CA based pedestrian models have similar characteristics. They have front and lateral movement models. The pedestrian moving logic is based on the car following concepts. We have developed our CA model based on the existing CA models as follows:

\section{- Front Movement Model}

Velocity is renewed with acceleration, reduction rules. After then, According to $p_{\text {noise }}$, involuntary reduction of pedestrian is explained. These acceleration, reduction rules and irregular reduction probability rule are decided pedestrian velocity determination process. They consist of 4 steps.

Step 1 : Effective spatial evaluation

$$
\begin{array}{r}
\text { If } \operatorname{gap}_{f} \geq v_{\max } \text { or } \operatorname{gap}_{l} \geq v_{\max } \text { or } \operatorname{gap}_{r} \geq v_{\max }, \\
\therefore g a p_{f}(t)=v_{\max }
\end{array}
$$




$$
\begin{gathered}
\operatorname{gap}_{f}>1 \text { and } g a p=\min \left[\text { gap }_{l}, \text { gap }_{r}\right] \\
\text { If } g^{g a p}<\operatorname{gap}_{f}, \\
\quad \text { if } p_{d g} \geq p_{r}, \\
\therefore \quad \operatorname{gap}_{f}(t)=\operatorname{gap}_{f}-1 \\
\quad \text { if } p_{d g}<p_{r}, \\
\therefore \quad \operatorname{gap}_{f}(t)=\operatorname{gap}_{f} \\
\text { If } \operatorname{gap}_{2} \geq \operatorname{gap}_{f}, \\
\therefore \quad \operatorname{gap}_{f}(t)=\operatorname{gap}_{f}
\end{gathered}
$$

Step 2 : Regulation of acceleration and deceleration

If the front gap is bigger than velocity of time $(\mathrm{t})$, it makes velocity of time $(\mathrm{t}+1)$ increase as acceleration per unit $(1 \mathrm{cell} / \mathrm{sec})$, It is not able to exceed a maximum speed $\left(v_{\max }\right)$.

$$
\begin{gathered}
\text { If } v(t) \geq \operatorname{gap}_{f}(t), \\
\therefore \quad v(t+1)=\min \left[v(t)+1, v_{\text {max }}\right]
\end{gathered}
$$

If the front is smaller than velocity of time $(\mathrm{t})$, it makes velocity of time $(\mathrm{t}+1)$ decrease.

$$
\begin{gathered}
\text { If } v(t) \geq \operatorname{gap}_{f}(t) \\
\therefore \quad v(t+1)=\operatorname{gap}_{f}(t)
\end{gathered}
$$

Step 3 : Irregular deceleration

If irregular reduction probability is bigger than involuntary sampling probability, It makes deceleration per unit (1cell/sec) decrease.

$$
\begin{gathered}
\text { If } p_{\text {noise }}<P_{r} \\
\text { If } v(t+1)>0 \\
\therefore \quad v(t+1)=\max [v(t+1)-1,0]
\end{gathered}
$$

If irregular reduction probability is smaller than involuntary sampling probability, acceleration $\&$ reduction rules have velocity.

$$
\begin{gathered}
\text { If } p_{\text {noise }}<P_{r} \\
\therefore \quad v(t+1)=\max [v(t+1), 0]
\end{gathered}
$$

Step 4 : Pedestrian front movement rule

It moves to front as renewal velocity

$$
x(t+1)=x(t)+v(t+1)
$$

\section{- Lateral Movement Model}

Lateral movement model is divided into 3 types.

1) The compulsive path alteration of the pedestrians

If time step is odd,

Front condition: if pedestrian is within recognition distance, 
If probability condition: if $p_{0} \geq p_{r}$

$\therefore \quad$ Change the route to left lateral

If time step is even,

Front condition: if right side cell is not occupied,

If probability condition: if $p_{0} \geq p_{r}$

$\therefore$ Change the route to right lateral

2) Preference route change

It assumed that pedestrian doesn't walk for straight line.

If $v(t)=v_{\text {max }}$, Pedestrian is not within a front recognition distance

Lateral condition: If time step is odd, left cell is not occupied

Front condition: $\operatorname{gap}_{f}(t) \leq \operatorname{gap}_{l}$

If probability condition: if $p_{m} \geq p_{r}$,

$\therefore$ Change the route to left lateral

Lateral condition: if time step is even, right cell is not occupied

Front condition: $\operatorname{gap}_{f}(t) \leq \operatorname{gap}_{l}$

If probability condition: if $p_{m} \geq p_{r}$,

$\therefore$ Change the route to right lateral

3) Travel time optimization for route change

Pedestrian changes their route to optimize travel time is less than $v(t)<v_{\max }$,

Pedestrian is not within a front recognition distance.

Lateral condition: If time step is odd, left cell is not occupied

Front condition: $\operatorname{gap}_{f}(t) \leq \operatorname{gap}_{l}$

If probability condition: if $p_{l} \geq p_{r}$,

$\therefore$ Change the route to left lateral

Lateral condition: If time step is even, right cell is not occupied

Front condition: $\operatorname{gap}_{f}(t) \leq \operatorname{gap}_{l}$

If probability condition: if $p_{l} \geq p_{r}$,

$\therefore$ Change the route to right lateral

Where,

$g_{f}:$ The number of cell with the front pedestrian

$g l:$ The number of cell with the left-front pedestrian

$g r:$ The number of cell with the right-front pedestrian

$v(t)$ : The number of cell with the pedestrians at time (t)

$v_{\max }:$ The maximum number of pedestrians (cell/EA)

$x(t)$ : The location of the pedestrian cell at time(t) 
$g a p^{f}(t)$ : Adjusted cell number with the front pedestrian

$p_{\text {noise }}:$ Irregular decelerated probability

$p_{r}:$ Random extracted probability

$D_{p}$ : Recognition distance for the front-opposite pedestrian

$p_{d g}$ : The decelerated probability of the front gap

$p_{o}$ : The probability of compulsive path change

$p_{m}$ : The probability of the path change at maximum speed

$p_{l}$ : The probability of the path change below maximum speed

The difference between the model developed and the existing models is mainly that the developed model allows some flexibility to reflect some pedestrian characteristics such as a group of pedestrian moving, and diagonal overtaking rules. These are important pedestrian characteristics observed in streets. Figure 1 shows the diagonal overtaking rules.

Moving direction

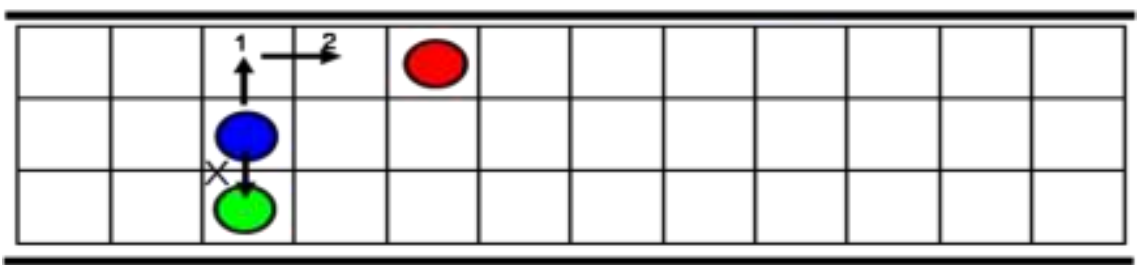

Existing models

Moving direction

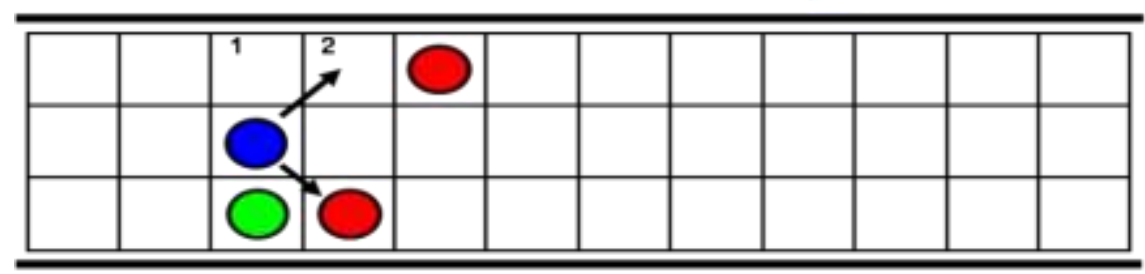

Developed models

Figure 1. Lateral Moving Models

Figure 2 shows a group of pedestrian moving together. The characteristics of the pedestrians may result in differences on the purpose of travels like shopping, leisure, commuting, and so on. Therefore, we expect another result as group of pedestrians simulates. 


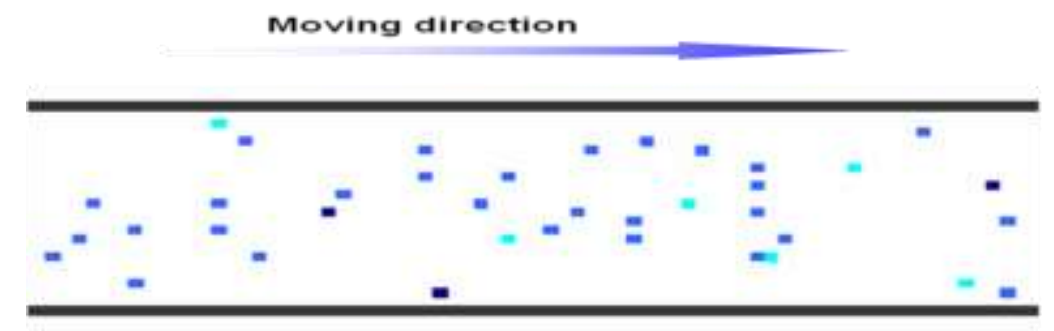

Existing models

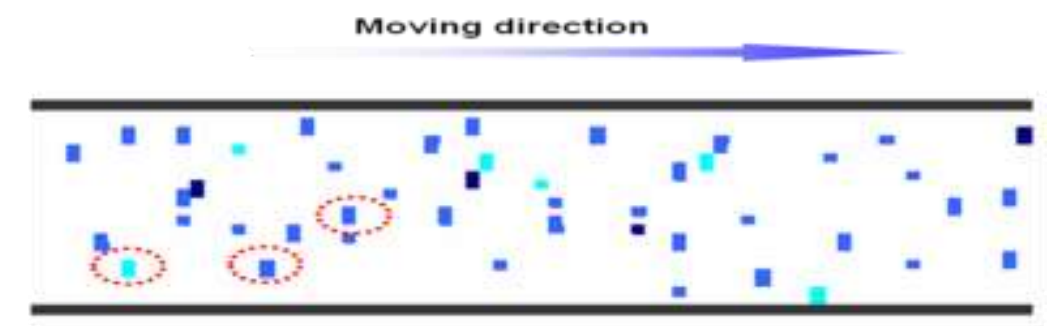

Developed models

Figure 2. Front Moving Models

\section{Case Studies using Pedestrian Simulation}

\subsection{Some Characteristics in Subways}

The sites selected for the study are 'Chungmu-ro' and 'Sa-dang' subway stations. The investigation time selected is between 7.00am and 9.00am which according to the videotapes from the stations is the peak time.

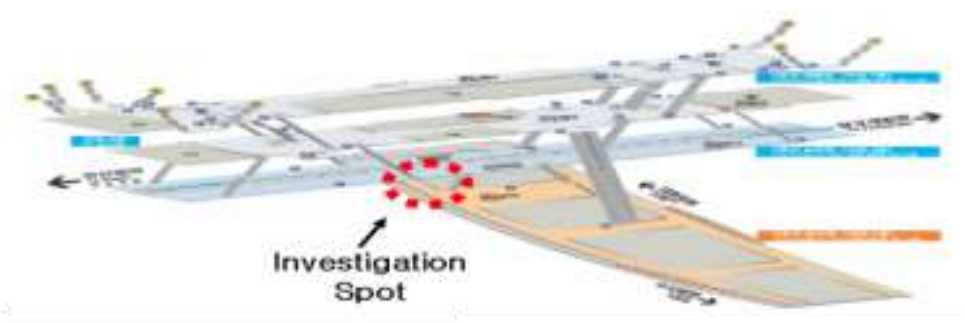

Chung mu- ro subway station

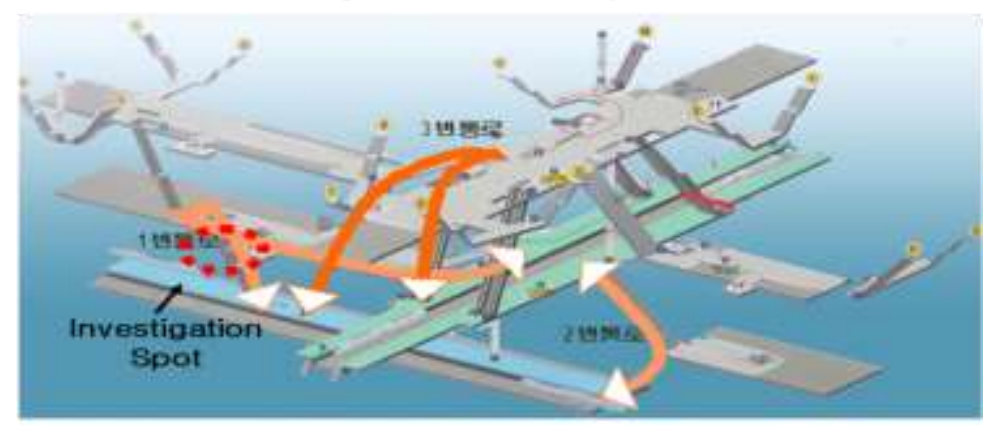

Sa-dang subway station

Figure 3. Case Study Stations

The result of the site investigation shows two major conclusions. First, when a group of pedestrians is collided with another group, their speed is decreased. Secondly, although each group of pedestrians takes wide occupied area at the beginning of the staircase, as the 
groups advance through the stairs, an oblique boundary line is formed by the group of pedestrians of the opposite sides.
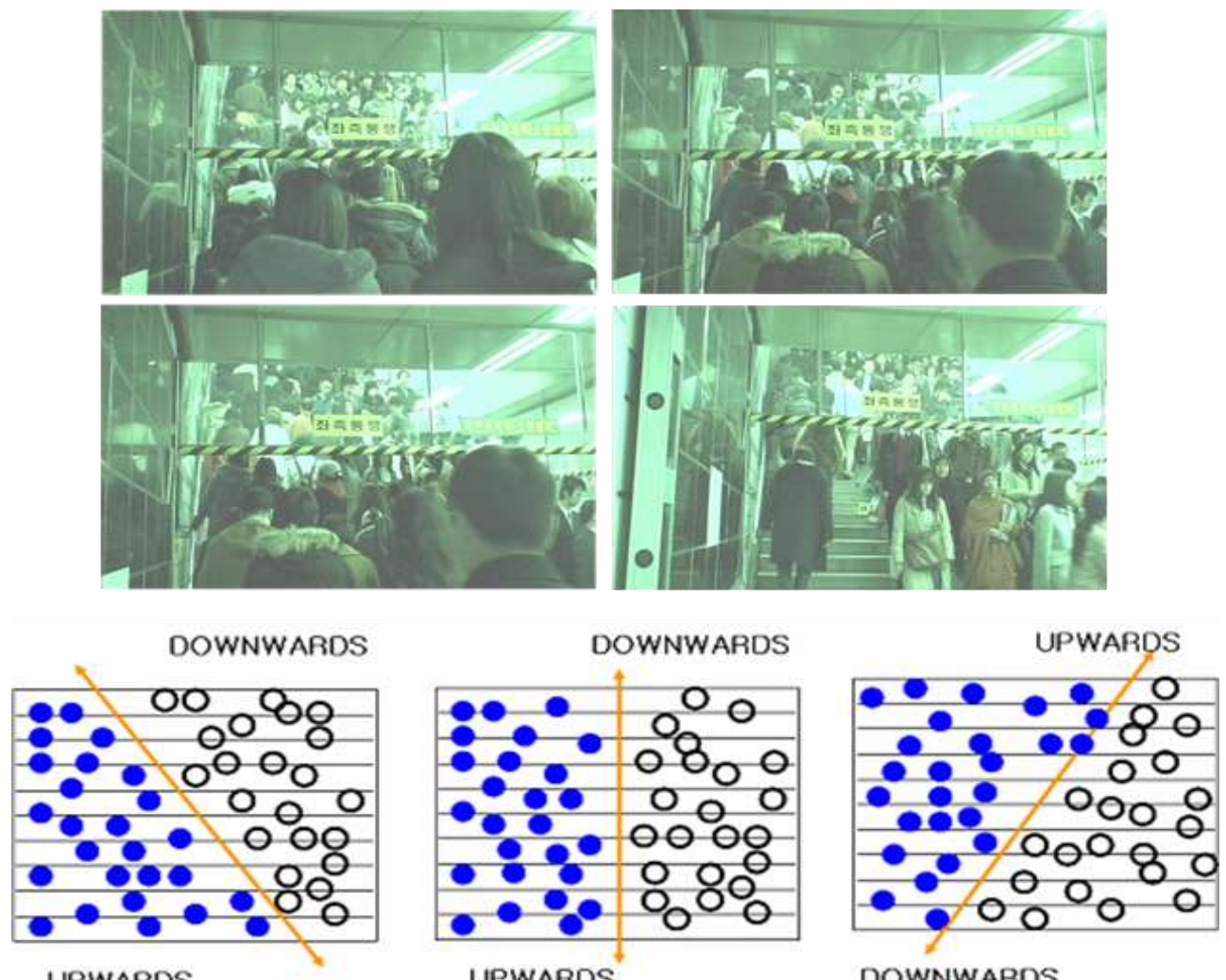

Figure 4. Crowded Pedestrian Movements

In these causes of walking habits, there are two aspects. One is a geometry construction of stairs, the other one is a pedestrian. In a geometry construction aspect, the problem is a decreasing sight of pedestrians by different size of steps. Pedestrians cannot see well at stairs, and a recognizable distance of the pedestrians is getting close. In the pedestrian's aspect, when they collide with pedestrians of opposite side, they intend to move left side. Pedestrians who need to transfer make a group of pedestrians naturally. And, when subway arrives to the station, the pedestrians who get off from a train intend to follow the front person. These characteristics make a group of pedestrians naturally. Unlike road, walking space has no median strip, so, moving of pedestrian is free. Definitely, even if there are signs which notice "Keep to the left" and in the special case, there is a median strip that is for pedestrian. If high density group of pedestrian is made, that signs are no good.

These walking habits can be explained from two view points. One is the geometrical design of the staircase and the other is pedestrian's behavior. In the geometrical design aspect, due to the change between down warding and up warding of stairs, the pedestrian's perceptive distance to the others coming from the opposite direction shortens. In the pedestrian's behavior aspect, when people collide with others coming from the opposite side, they tend to move towards the left side and a group is naturally formed. When a subway arrives at the platform, the people getting off from it tend to follow the front person and a group is naturally formed. Unlike road, walking space has no median strip, and pedestrians move freely. Even though there are "Keep Left" signs or median strips for pedestrians, if the density of pedestrians at the stairway is already high, they would not comply.

There are three steps in a walking simulation. The first step is an input of data and a simulation initialization. In this module, the data to be input is walking data, network data 
and various variables for simulation. The second step is a simulation process; pedestrian generation, pedestrian influx, and side and forward moving. The third step is an analysis of the output and findings.

Table 1. Comparison between Real Data and Simulation

\begin{tabular}{|c|c|c|c|}
\hline \multicolumn{2}{|c|}{ Classification } & $\begin{array}{l}\text { Speed of Pedestrian } \\
\qquad(\mathrm{m} / \mathrm{min})\end{array}$ & $\begin{array}{l}\text { Pedestrian rate of flow } \\
\text { (ped } / \mathrm{m} / \mathrm{min} \text { ) }\end{array}$ \\
\hline \multirow{2}{*}{$\begin{array}{l}\text { Output of } \\
\text { Real data }\end{array}$} & $\begin{array}{c}\text { Up } \\
\text { wards }\end{array}$ & 36.6 & 35.9 \\
\hline & $\begin{array}{l}\text { Down } \\
\text { wards }\end{array}$ & 37.8 & 34.6 \\
\hline \multirow{2}{*}{$\begin{array}{l}\text { Output of } \\
\text { Simulation }\end{array}$} & $\begin{array}{c}U p \\
\text { wards }\end{array}$ & 37.2 & 31.8 \\
\hline & $\begin{array}{l}\text { Down } \\
\text { wards }\end{array}$ & 39.6 & 35.0 \\
\hline
\end{tabular}

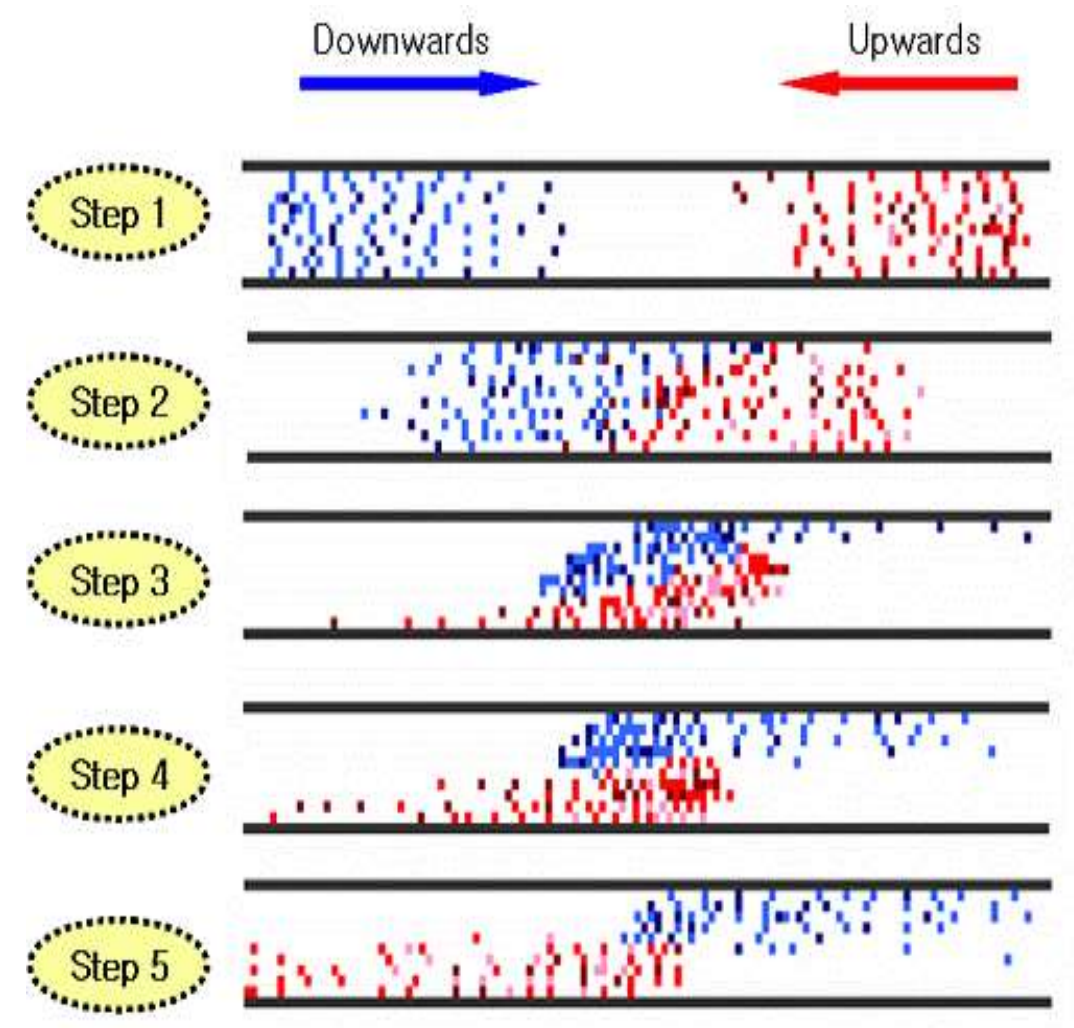

Figure 5. Simulation Phases

There are five scenarios in this study. The scenarios are classified by the pedestrian rate of flow. In Korea, the stair's level of service (LOS) is decided by KHCM (Korean Highway Capacity Manual). According to the manual, the LOS of stairs only depends on whether there are groups of pedestrians or not, however, the detailed pedestrian ratio of each group is not considered. The five scenarios by the pedestrian LOS can be found as follows. 
Table 2. Pedestrian Flow Rate on KHCM Classified by LOS

\begin{tabular}{|c|c|c|c|c|c|}
\hline & $\begin{array}{c}\text { Scenario 1 } \\
\text { (LOS A) }\end{array}$ & $\begin{array}{c}\text { Scenario 2 } \\
\text { (LOS B) }\end{array}$ & $\begin{array}{c}\text { Scenario 3 } \\
\text { (LOS C) }\end{array}$ & $\begin{array}{c}\text { Scenario 4 } \\
\text { (LOS D) }\end{array}$ & $\begin{array}{c}\text { Scenario 5 } \\
\text { (LOS E) }\end{array}$ \\
\hline $\begin{array}{c}\text { Pedestrian } \\
\text { rate of flow } \\
(\mathrm{ped} / \mathrm{min} / \mathrm{m})\end{array}$ & 43 & 50 & 65 & 69 & 74 \\
\hline
\end{tabular}

\subsection{Parameter Adjustment for Simulating Various Fence Scenarios}

There is generally a difference between the velocities of the pedestrians moving upwards and the ones moving downwards. In this study, the velocity of upward bound pedestrians is set to $2 \mathrm{cell} / \mathrm{sec}$ and the one of downward bound pedestrians is set to $3 \mathrm{cell} / \mathrm{sec}$. The perceptive distance to the pedestrians coming from opposite direction is adjusted to $2 \sim 3 \mathrm{~m}$. In order to adopt the pedestrian's behavior, the possibility that people move towards the left side when they collide with others is set up to 0.999. The possibility of pedestrian's changing lanes at maximum velocity is set up to 0.2 .

According to the simulation results, the higher the pedestrian rate of flow, the bigger the difference in pedestrian's velocity with regards to the existence of fence. The difference in pedestrian's velocity between the full fence model and the extended one is not as considerable as the one between the full fence model and partial one. In scenario 1, the pedestrian's velocity without a fence has shown $80 \mathrm{~m} / \mathrm{min}$ and both the velocities of full and extended fences showed $84 \mathrm{~m} / \mathrm{min}$. However, in scenario 2 to 5 , there is a significant difference regarding the existence of a fence. Between the four models, the widest gap is shown in scenario 3.

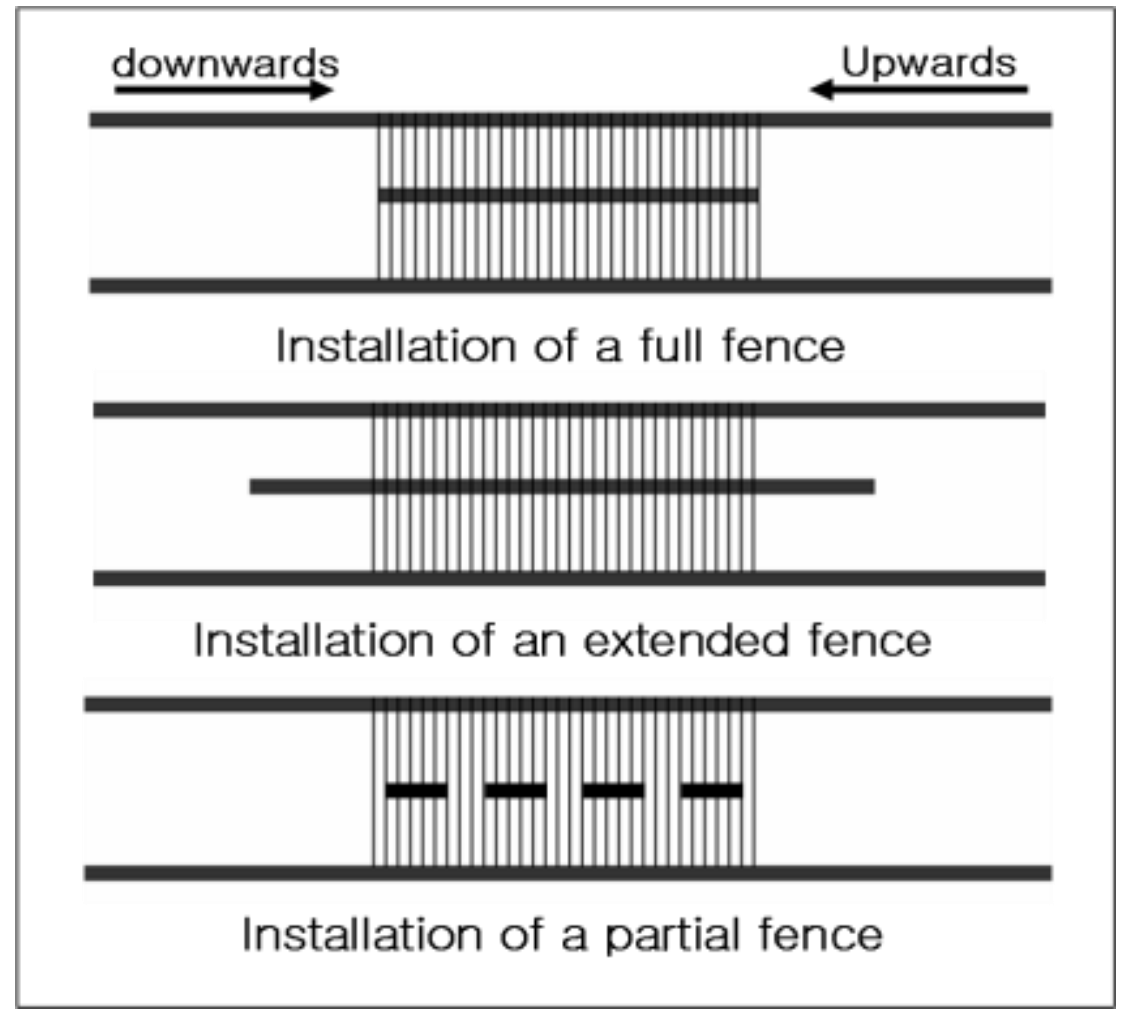

Figure 6. Central Fence Layout Designs 
Table 3. Simulation Results on Various Fence Layout Designs

\begin{tabular}{|c|c|c|c|c|c|}
\hline $\begin{array}{c}\text { LOS } \\
\text { Scenarios }\end{array}$ & $\begin{array}{c}\text { Pedestrian } \\
\text { rate of flow } \\
(\mathrm{ped} / \mathrm{min} / \mathrm{m})\end{array}$ & $\begin{array}{c}\text { No fence } \\
\text { case } \\
(\mathrm{m} / \mathrm{min})\end{array}$ & $\begin{array}{c}\text { Full fence } \\
\text { case } \\
(\mathrm{m} / \mathrm{min})\end{array}$ & $\begin{array}{c}\text { Extended } \\
\text { fence case } \\
(\mathrm{m} / \mathrm{min})\end{array}$ & $\begin{array}{c}\text { Partial fence } \\
\text { case } \\
(\mathrm{m} / \mathrm{min})\end{array}$ \\
\hline 1 (LOS A) & $<43$ & 80 & 84 & 84 & 81 \\
\hline $2($ LOS B) & $<50$ & 74 & 81 & 82 & 78 \\
\hline $3($ LOS C) & $<65$ & 68 & 77 & 78 & 70 \\
\hline $4($ LOS D) & $<69$ & 58 & 65 & 67 & 60 \\
\hline $5($ LOS E) & $<74$ & 53 & 61 & 62 & 55 \\
\hline
\end{tabular}

\subsection{Evaluation of Various Fence Layout Designs}

This study evaluates the representation of reality of the model by analyzing the velocities of a group of pedestrians regarding the location of a fence at transferring stairs in 'Sa-dang' subway station where lines 2 and 4 transfer together. It was presumed that there was a huge collision between the pedestrian groups coming from opposite directions since the interval of the subways is only $2 \sim 4 \mathrm{mins}$, however, based on the investigation of the station, there was no critical collision between the two lines since there is a very long transferring stairway. Therefore, this study is conducted in two situations and in three designs in five levels of services scenarios as follows.

- Case 1: upward bound pedestrians are heavier than the downward bound ones.

- Case 2: downward bound pedestrians are heavier than the upward bound ones.

- Design 1: a fence dividing the entire stairway.

- Design 2: a partial fence at the upper area of the stairway.

- Design 3: a partial fence at the lower area of the stairway.

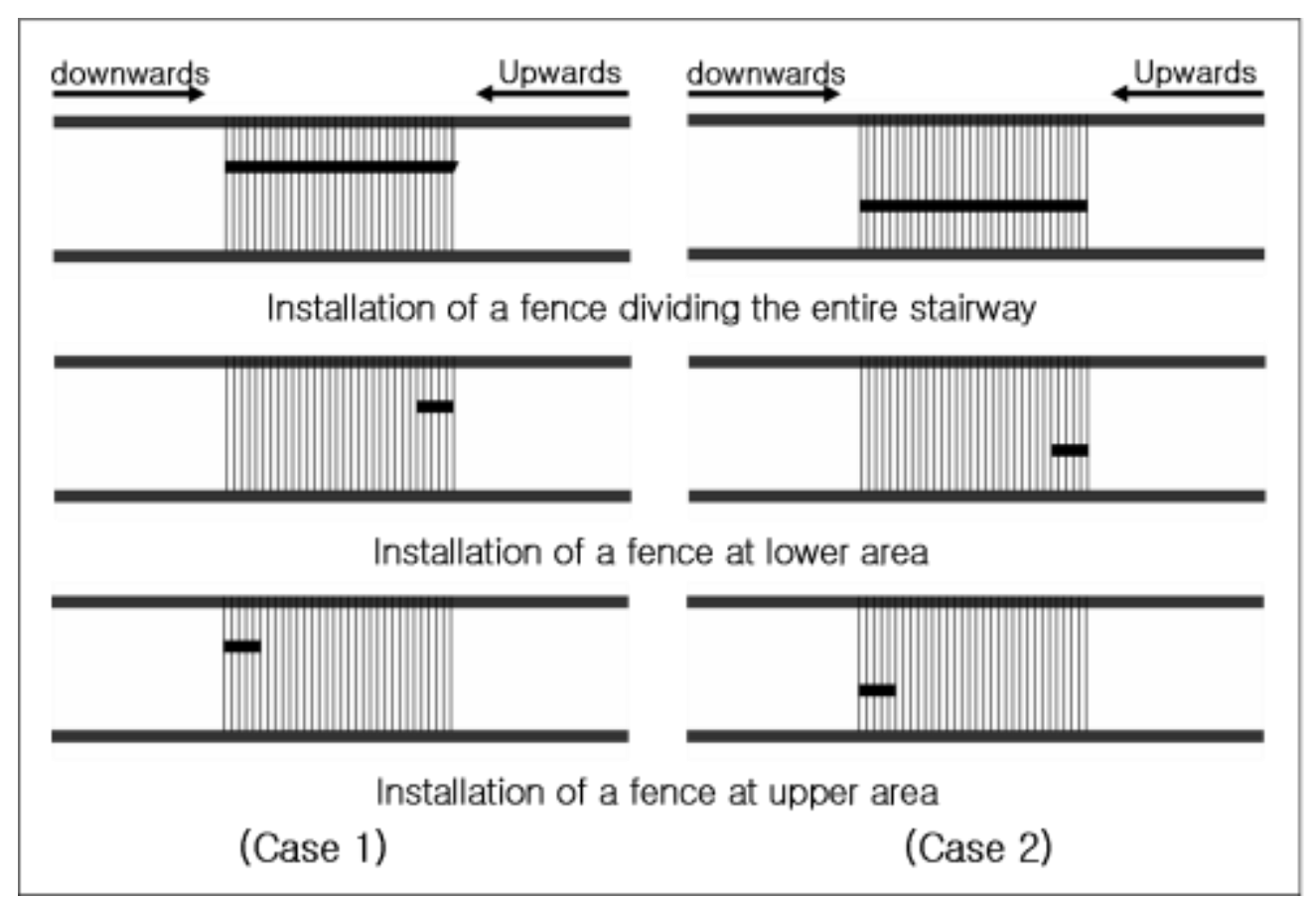

Figure 7. Fence Layout Designs 
The roles of fence in a stairway are to decrease the collision between people moving upwards and downwards, and to increase their walking speed at congested conditions. As mentioned, in general, upward pedestrian speed is different from the downward one. In this study, the parameters are set as follows.

- Upward bound pedestrian's Velocity: 2cell/sec

- Downward bound pedestrian's Velocity: 3cell/sec

- Perceptive distance to the pedestrians coming from the opposite direction: $2 \sim 3 \mathrm{~m}$.

- The possibility of lane change to the left when there is a collision: 0.999

- Possibility of lane change when pedestrians move at maximum velocity: 0.2

\section{Case 1: Upward Bound Pedestrians are Heavier than the Downward Bound One}

This simulation assumes that there is no huge collision and that there are a lot more people who are moving upwards than downwards.

Table 4. Heavier Upward Pedestrians than Downward One

\begin{tabular}{|c|c|c|c|c|c|c|c|c|c|}
\hline \multirow{2}{*}{$\begin{array}{c}\text { LOS } \\
\text { Scenarios }\end{array}$} & \multirow{2}{*}{$\begin{array}{l}\text { Pedestrian } \\
\text { rate of flow } \\
(\mathrm{ped} / \mathrm{min} / \mathrm{m})\end{array}$} & \multicolumn{2}{|c|}{$\begin{array}{l}\text { No fence case } \\
(\mathrm{m} / \mathrm{min})\end{array}$} & \multicolumn{2}{|c|}{$\begin{array}{c}\text { Full fence case } \\
(\mathrm{m} / \mathrm{min})\end{array}$} & \multicolumn{2}{|c|}{$\begin{array}{l}\text { Upper fence case } \\
(\mathrm{m} / \mathrm{min})\end{array}$} & \multicolumn{2}{|c|}{$\begin{array}{l}\text { Lower fence case } \\
\qquad(\mathrm{m} / \mathrm{min})\end{array}$} \\
\hline & & $\begin{array}{c}\text { Downwa } \\
\text { rds }\end{array}$ & $\begin{array}{c}\text { Up } \\
\text { wards }\end{array}$ & $\begin{array}{l}\text { Down } \\
\text { wards }\end{array}$ & $\begin{array}{c}\text { Up } \\
\text { wards }\end{array}$ & $\begin{array}{l}\text { Down } \\
\text { wards }\end{array}$ & $\begin{array}{c}\text { Up } \\
\text { wards }\end{array}$ & $\begin{array}{l}\text { Down } \\
\text { wards }\end{array}$ & $\begin{array}{c}\text { Up } \\
\text { wards }\end{array}$ \\
\hline $1(\operatorname{LOS} A)$ & $<43$ & 82 & 80 & 88 & 83 & 84 & 82 & 82 & 82 \\
\hline $2(\operatorname{LOS} B)$ & $<50$ & 75 & 73 & 84 & 79 & 79 & 77 & 78 & 76 \\
\hline 3(LOS C) & $<65$ & 67 & 66 & 77 & 72 & 74 & 72 & 73 & 71 \\
\hline 4(LOS D) & $<69$ & 60 & 57 & 70 & 65 & 64 & 62 & 61 & 60 \\
\hline 5(LOS E) & $<74$ & 53 & 50 & 65 & 60 & 59 & 57 & 56 & 54 \\
\hline
\end{tabular}

In the result, it can be found that the higher the pedestrian rate of flow is, the bigger the difference in pedestrian velocities with regards to the existence of fence is. According to the simulation, the pedestrian's velocity where the fence divides the entire stairway is the highest. This may be caused since the fence separates the two sides completely, thus minimizing collision and insuring a faster passage than the other models. In the two partial fence models, the velocity of upper fence model is slightly higher than the one of the lower one as, in this case, the groups of upward bound pedestrians are more than of downward bound ones. The groups of downward bound pedestrians recognize the upper fence from the beginning and then walk on the left side of the fence which limits the collision with upward bound pedestrians. Therefore, where the upward bound pedestrians are more than downward bound ones, the best decision would be to install either a fence covering the whole stairway or a partial fence on the upper side of the stairway.

\section{Case 2: Downward Bound Pedestrians are Heavier than Upward Bound Ones}

This simulation assumed that there is no huge collision and that there are a lot more people moving downward than upward. 
Table 5. Heavier Downward Pedestrians than Upward One

\begin{tabular}{|c|c|c|c|c|c|c|c|c|c|}
\hline \multirow{2}{*}{$\begin{array}{c}\text { LOS } \\
\text { Scenarios }\end{array}$} & \multirow{2}{*}{$\begin{array}{l}\text { Pedestrian } \\
\text { rate of flow } \\
(\mathrm{ped} / \mathrm{min} / \mathrm{m})\end{array}$} & \multicolumn{2}{|c|}{$\begin{array}{l}\text { No fence case } \\
(\mathrm{m} / \mathrm{min})\end{array}$} & \multicolumn{2}{|c|}{$\begin{array}{l}\text { Full fence Case } \\
(\mathrm{m} / \mathrm{min})\end{array}$} & \multicolumn{2}{|c|}{$\begin{array}{l}\text { Upper fence case } \\
(\mathrm{m} / \mathrm{min})\end{array}$} & \multicolumn{2}{|c|}{$\begin{array}{l}\text { Lower fence case } \\
(\mathrm{m} / \mathrm{min})\end{array}$} \\
\hline & & $\begin{array}{c}\text { Downwa } \\
\text { rds }\end{array}$ & $\begin{array}{c}\mathrm{Up} \\
\text { wards }\end{array}$ & $\begin{array}{l}\text { Down } \\
\text { wards }\end{array}$ & $\begin{array}{c}\mathrm{Up} \\
\text { wards }\end{array}$ & $\begin{array}{l}\text { Down } \\
\text { wards }\end{array}$ & $\begin{array}{c}\mathrm{Up} \\
\text { wards }\end{array}$ & $\begin{array}{l}\text { Down } \\
\text { wards }\end{array}$ & $\begin{array}{c}\text { Up } \\
\text { wards }\end{array}$ \\
\hline $1(\operatorname{LOS} A)$ & $<43$ & 82 & 80 & 85 & 87 & 83 & 81 & 83 & 83 \\
\hline $2(\operatorname{LOS} \mathrm{B})$ & $<50$ & 75 & 73 & 81 & 82 & 79 & 75 & 81 & 78 \\
\hline $3(\operatorname{LOS} C)$ & $<65$ & 67 & 66 & 76 & 76 & 71 & 68 & 73 & 72 \\
\hline 4(LOS D) & $<69$ & 60 & 57 & 68 & 72 & 62 & 58 & 64 & 64 \\
\hline $5($ LOS E) & $<74$ & 53 & 50 & 63 & 68 & 55 & 54 & 57 & 59 \\
\hline
\end{tabular}

We can observe followings through this simulation. The case of no fence has similar results as in the previous simulation. On the other hand, there are somewhat different results in full fence, upper fence, and lower fence cases. Indeed, it is reasonable that the effectiveness in the full fence scenario in pedestrian facilities is greater than any other cases. Therefore, where the downward bound pedestrians are heavier than upward bound ones, the best decision would be to install either a fence covering the whole stairway or at least a partial fence on the lower side of the stairway.

\subsection{Result of Study for Pedestrian Level of Service in Seoul}

The sites selected for the study for pedestrian level of service in Seoul are classified wide sidewalk and narrow sidewalk by standard system of node link in Seoul. In case of wide sidewalk, it means that width of sidewalk is over $12 \mathrm{~m}$ of arterial and collector, whereas narrow sidewalk means that subway station near the road in urban region/districts. Study for pedestrian level of service in Seoul is based on standard on KHCM. The overall pedestrian level of service in Seoul is shown in the figure below.

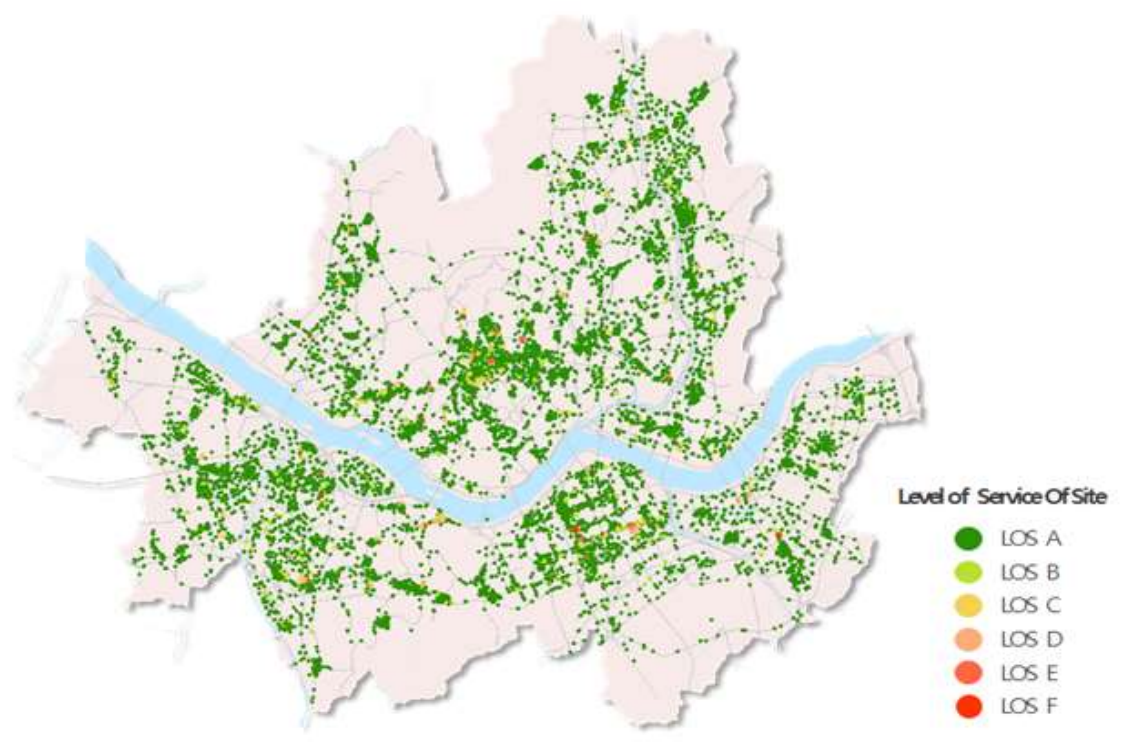

Figure 8. Level of Service in Seoul

The result of this study represents that difference between the high points and low points for pedestrian level of service is determined by the availability of pedestrian facilities such 
as pedestrian furniture. Therefore, pedestrian level of service depends on existence and appropriacy of street furniture such as bollard, available space of sidewalk, fences and waiting area of bus stops. If furniture in the way has set on inappropriate position, behavior of pedestrian would seem to avoid furniture and conflict between pedestrians occurs. These situations cause low points of level of service.

\subsection{Site Selection and Analysis of Pedestrian Behavior and Character}

One site of the classified as low level of service is selected as the site to be get the street furniture. There are the bus stops, fences, bollard and waiting area of bus stops at the selected site. These pedestrian facilities and furniture can affect the behavior and movements of pedestrians. Also, geometry of the road such as width and height can affect the speed of the pedestrians. In addition, these effects could be directly related to the level of service and primary cause of low level of service.

Table 6. Investigation of Site

\begin{tabular}{lrr}
\hline & Result of Survey & \multicolumn{1}{c}{ Remarks } \\
\hline Width of sidewalk & $2.4 \mathrm{~m}$ & - \\
Obstacles & 7 Bollards & To prevent vehicle \\
Bus stops area & Presence(1) & Road side \\
Merge and Diverge & Mall and Intersection & Mall entrance (9) \\
Height of the Sidewalk & Eastbound is high & - \\
\hline
\end{tabular}

Before supplying furniture to the selected site, the behavior and characteristics of the pedestrians in the selected site would be analyzed. There is a road side bus stop at the site. For bus passengers, a few people riding the bus represent behavior moving in the type of group. Whereas, for non bus passengers, they seems to move in a diagonal directions in order to stay away from bus waiting area. And due to a lot installed bollards at the sidewalk, a few people walking at the there have shown behavior to avoid pedestrian furniture. All of these pedestrian behaviors would be based on the goal of minimizing the travel time and maximizing their safety. So simulation model of pedestrians should be applied pedestrian's characteristics.

\subsubsection{Investigation of Pedestrian Movement through the Video Shoot}

Three elements of pedestrian traffic (pedestrian density, walking speed, pedestrian volume \& pedestrian flow rate) had been measured to identify the correlation of these factors by video camera installed at the site.

(1) Pedestrian density

Pedestrian density means the number of pedestrians in the unit area at any point in time. In this study, number of pedestrians had been observed on the stop screen every 10 seconds.

(2) Walking speed

Waking speed is the distance traveled by pedestrians during unit time. Measurement of the speed by video camera is hard because the small distance can't measure the exact walking speed. So it could be measured in the site by stopwatch.

(3) Pedestrian volume \& Pedestrian flow rate

Draw a line vertically to sidewalk and observe the number of pedestrians passed the line in order to measure in the screen during 10seconds. And this observed data convert the pedestrian density and pedestrian traffic flow according to pedestrian speed. 
Table 7. Result of Investigation

\begin{tabular}{crrr}
\hline Times/10secs & Density $\left(\mathrm{ped} / \mathrm{m}^{2}\right)$ & Flow(ped $/ \mathrm{m} \cdot \mathrm{min})$ & Speed(m/hour) \\
\hline 1st & 1.40 & 1.13 & 1.24 \\
2nd & 1.64 & 1.40 & 1.17 \\
3rd & 1.39 & 1.10 & 1.26 \\
4th & 1.04 & 0.99 & 1.05 \\
$\ldots$ & $\ldots$ & $\ldots$ & $\ldots$ \\
90th & 1.38 & 1.17 & 1.18 \\
\hline
\end{tabular}

\subsubsection{Relationship between Pedestrian Traffic Density and Traffic Flow at the Site}

Pedestrian characteristics data is analyzed by data on VTR every 10 seconds. Though data on VTR, pedestrian density, pedestrian traffic flow and pedestrian speed of each count was observed and distribution of density-flow was derived.

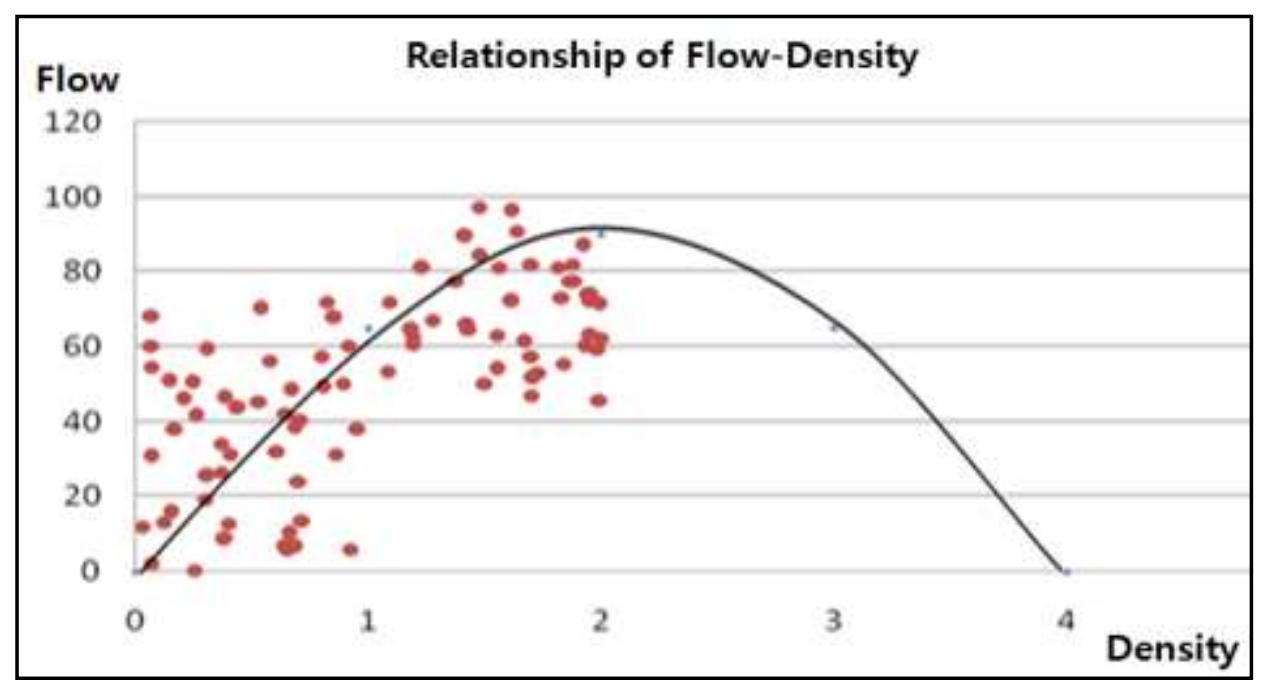

Figure 9. Distribution of Pedestrian Density-Flow

Calculated the density-flow equation is $\mathrm{q}=19.96 \mathrm{k} 2+73.31 \mathrm{k}, \mathrm{u}=19.96 \mathrm{k}+19.31$. And through this equation, the free speed, the critical speed, the critical density, the critical density and capacity at the site are analyzed $1.32 \mathrm{~m} / \mathrm{sec}, 0.66 \mathrm{~m} / \mathrm{s}, 3.97 \mathrm{ped} / \mathrm{m} 2,1.98 \mathrm{ped} / \mathrm{m} 2$ and $79 \mathrm{ped} / \mathrm{m} \cdot \mathrm{min}$ respectively.

\subsection{Pedestrian Simulation Model \& Validation of Parameter}

\subsubsection{Pedestrian Simulation Model by CA}

There are three steps in a pedestrian walking simulation. The first step is an input of data and a simulation initialization. In this module, the data to be input is walking data, network data and various variables for simulation. The second step is a simulation process; pedestrian generation, pedestrian influx, and side and forward moving. The third step is an analysis of the output and findings. 


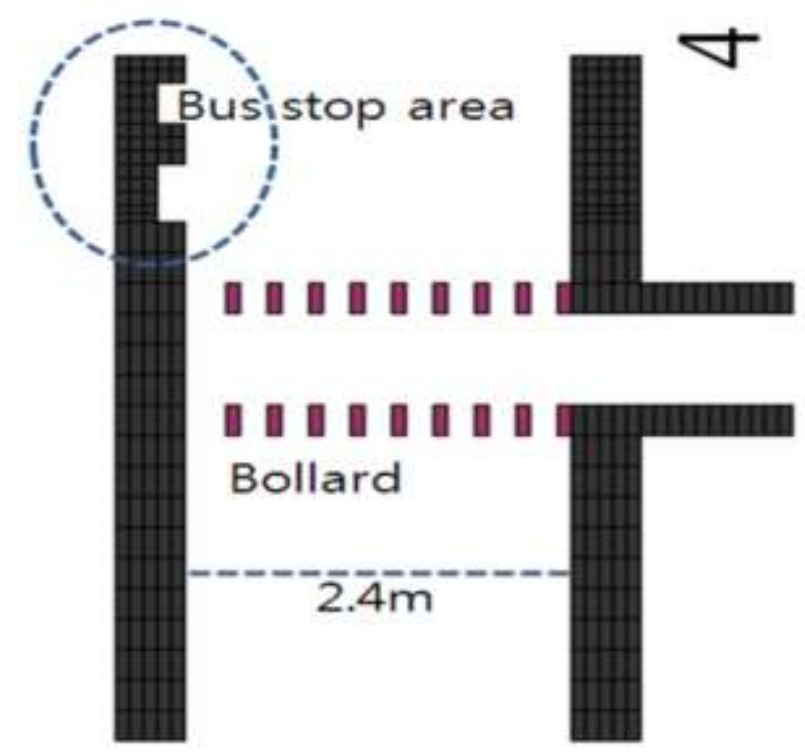

Figure 10. Network based on CA

Table 8. Comparison Data of Real with Simulation

\begin{tabular}{rrrr}
\hline & $\begin{array}{c}\text { Flow of } \\
\text { Pedestrian(ped/min) }\end{array}$ & $\begin{array}{c}\text { Speed of } \\
\text { Pedestrian }(\mathrm{m} / \mathrm{sec})\end{array}$ & $\begin{array}{c}\text { Pedestrian rate of } \\
\text { flow }(\mathrm{ped} / \mathrm{m} / \mathrm{min})\end{array}$ \\
\hline Real data & 216 & 0.92 & 53 \\
imulation & 216 & 0.90 & 51 \\
\hline
\end{tabular}

\subsubsection{Parameter Adjustment}

In order to validate the parameter of pedestrian simulation model, investigation of the width, flow rate of pedestrian, facilities, velocity of each direction and bus stop is performed and make adjustments for each parameter through field survey.

Prior to adjusting the parameters, the adjustment range of each parameter is set by referring to the various existing survey data and research reports. To establish the maximum possible adjustment, range of adjustment followed value presented in the Simwalk program. Additionally, range unit of adjusting parameter converse to appropriate in the CA model. The unit of value in Simwalk is converted into approximately 0.5 cells in CA model.

Table 9. Range of Adjustment based on Simwalk

\begin{tabular}{|c|c|c|}
\hline Classification & Range of Adjustment & Reliable Source \\
\hline Cell Size & $0.5 \mathrm{~m}$ & $\begin{array}{l}\text { Korea Research Institute of } \\
\text { Standards and Science }\end{array}$ \\
\hline Interaction & $1.2 \sim 3.6 \mathrm{~m}$ & Direction of Fruin \\
\hline $\operatorname{Speed}(\mathrm{m} / \mathrm{s})$ & $\begin{array}{r}\text { Average : } 0.94 \sim 1.62 \\
\text { Male : } 1.3 \text {, Female: } 1.21\end{array}$ & $\begin{array}{r}\text { Association of Road Safety } \\
\text { Research }\end{array}$ \\
\hline Agent Radius & $0.2 \mathrm{~m}^{2}$ & $\begin{array}{l}\text { Korea Research Institute of } \\
\text { Standards and Science }\end{array}$ \\
\hline Time Step & $0.5 \sim 1.0$ & Manual of Simwalk \\
\hline
\end{tabular}


There is generally a difference between the velocities of pedestrian's movements in different directions. In this study, the velocity of east bound pedestrians is set to $2 \mathrm{cell} / \mathrm{sec}$ and the one of west bound pedestrians is set to $3 \mathrm{cell} / \mathrm{sec}$. The perceptive distance to the pedestrians coming from opposite direction is adjusted to $2 \sim 3 \mathrm{~m}$. In order to adopt the pedestrian's behavior, the possibility that people move towards the left side when they collide with others is set up to 0.999 . The possibility of pedestrian's changing lanes at maximum velocity is set up to 0.2 . The case of interaction range, it means that distance for pedestrian to start to avoid things while recognizing the direction. In order to adjust it, the direction of Fruin is used to perform simulation. Through pedestrian behavior modeling, we decide that the value of $2.5 \mathrm{~m}$ is the most rational decision as the distance for pedestrian to start to avoid things. The case of velocity of $1.25 \mathrm{~m} / \mathrm{s}$, it means that the weighted average value based on male/female average speed and field survey data. For the agent radius, although it presented in the Korea Institute of Standards as $0.13 \mathrm{~m} 2$, the selected value is $0.2 \mathrm{~m} 2$. Because the value of $0.2 \mathrm{~m} 2$ could be considered the minimum space that thickness of clothing and space between mans.

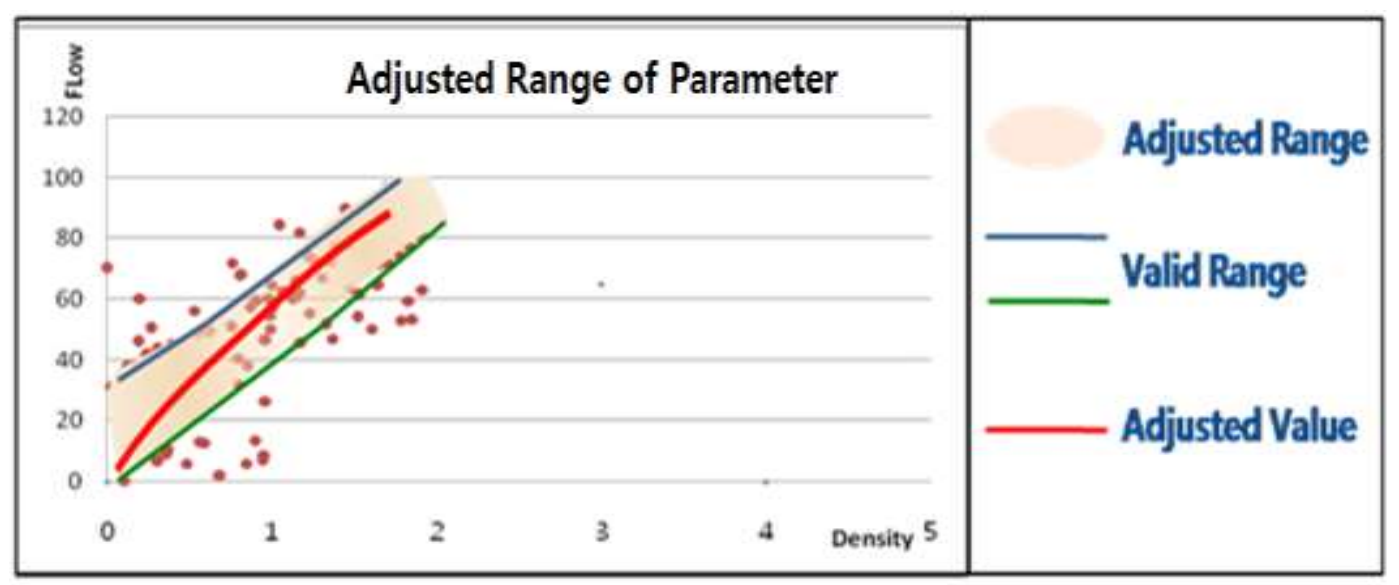

Figure 11. Adjusting Rage of Parameter

\subsection{Creating Scenario for Applying to Model.}

All of scenarios are analyzed according to the pedestrian rate of flow in each direction which would be eastbound and westbound. Mark on sidewalk is set to reduce conflict between bus passengers. Conflict between pedestrians can affect pedestrian rate of flow and velocity which are measurement of effectiveness for level of service. Therefore, we will compare and analyze pedestrian velocity and flow rate of result before and after by simulation. In next scenario, changing the number of bollard installed on the sidewalk would be variable. The bollard on the sidewalk can cause conflict between pedestrian and obstacle. Conflict caused by bollard can affect velocity of pedestrian. Because velocity of pedestrian is measurement of effectiveness for level of service, we will compare and analyze pedestrian velocity of result before and after by simulation. In last scenario Current width of sidewalk is $2.4 \mathrm{~m}$ and it can affect capacity. And capacity of sidewalk affect pedestrian rate of flow, occupied space, density and velocity which are measurement of effectiveness for level of service. The width of sidewalk set $2.8 \mathrm{~m}$ to provide extra space to pedestrian. Through changing the width of sidewalk, we will compare and analyze pedestrian rate of flow as measure of effectiveness for level of service. 


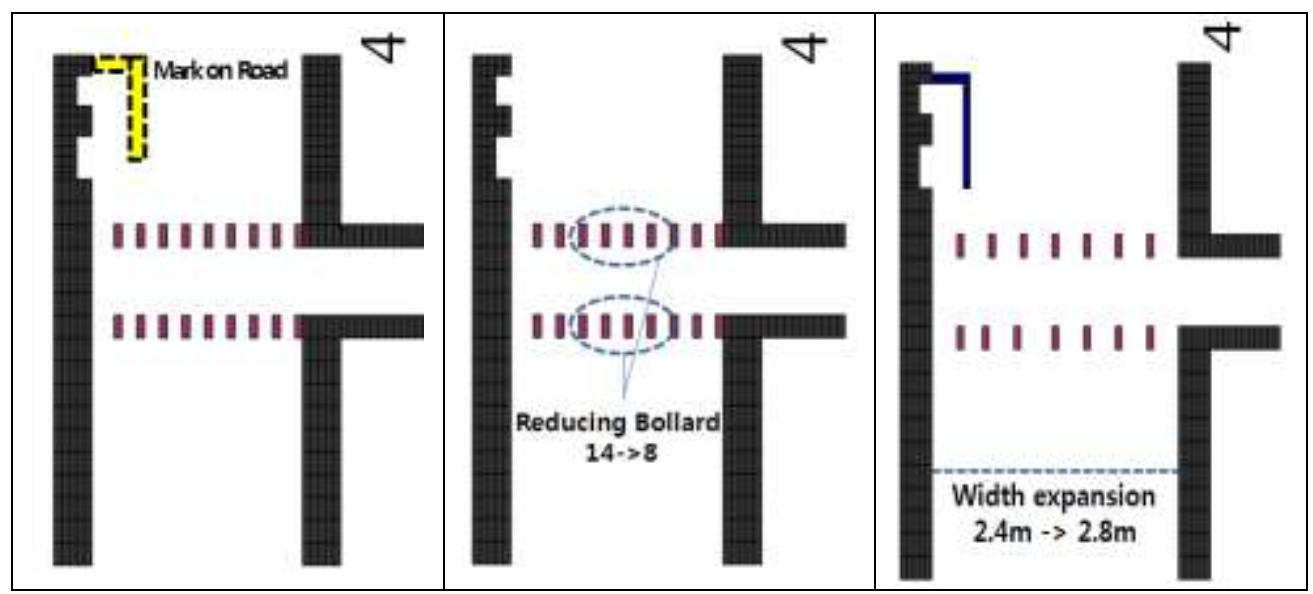

Figure 12. Street Furniture at the Site

The below table is level of service according to the measurement of effectiveness. This study would analyze effectiveness caused by supplying pedestrian furniture based on this table in KHCM.

Table 10. Pedestrian Level of Service

\begin{tabular}{ccccc}
\hline Classification & $\begin{array}{c}\text { Rate of flow } \\
(\mathrm{ped} / \mathrm{min} / \mathrm{m})\end{array}$ & $\begin{array}{c}\text { Occupied pace } \\
\left(\mathrm{m}^{2} / \mathrm{ped}\right)\end{array}$ & $\begin{array}{c}\text { Density } \\
\left(\mathrm{ped} / \mathrm{m}^{2}\right)\end{array}$ & $\begin{array}{c}\text { Velocity } \\
(\mathrm{m} / \mathrm{sec})\end{array}$ \\
\hline LOS A & $\leq 20$ & $\geq 3.3$ & $\leq 0.3$ & $\geq 75$ \\
LOS B & $\leq 32$ & $\geq 2.0$ & $\leq 0.5$ & $\geq 72$ \\
LOS C & $\leq 46$ & $\geq 1.4$ & $\leq 0.7$ & $\geq 69$ \\
LOS D & $\leq 70$ & $\geq 0.9$ & $\leq 1.1$ & $\geq 62$ \\
LOS E & $\leq 106$ & $\geq 0.38$ & $\leq 2.6$ & $\geq 40$ \\
\hline
\end{tabular}

Source : Korea Highway Capacity Manual

\subsection{Evaluation of Each Scenario by CA}

By supplying street furniture, level of service of pedestrian environment would be compared before and after and verify the effectiveness of facilities. Level of service for Scenario 1 which marked at bus stop area is calculated by pedestrian traffic flow rate and average pedestrian speed as measurement of effectiveness. Level of service for Scenario 2 which reduced the number of bollard installed is calculated by duration and average pedestrian speed as measurement of effectiveness. And last, level of service for scenario 3 which expand the width of sidewalk $04 . \mathrm{m}$ is calculated by duration and pedestrian speed. The reason why each scenario selects those measurement of effectiveness is that:

(1) Mark on sidewalk is set to reduce conflict between bus passengers and pedestrians. Conflict between pedestrians and passengers can have the most impact pedestrian rate of flow and velocity. 
(2) Reducing the number of bollard installed on the sidewalk would decrease conflict between pedestrian and bollard. Conflict caused by bollard can affect velocity of pedestrian and duration related with it.

(3) Width of sidewalk related with capacity can affect pedestrian rate of flow, occupied space, density and velocity. Of these, we compared and analyzed pedestrian rate of flow and duration as measure of effectiveness for level of service.

\subsection{Scenario Simulation by CA model}

- Eastbound \& westbound pedestrian's Velocity: 2cell/sec \& 3cell/sec

- Perceptive distance to the pedestrians coming from the opposite direction: 2 3m.

- The possibility of lane change to the left when there is a collision: 0.999

- Possibility of lane change when pedestrians move at maximum velocity: 0.2

Table 11. Result of Simulation

\begin{tabular}{c|crr}
\hline Scenario & M.O.E & Before & After \\
\hline $\begin{array}{c}\text { Mark on sidewalk at } \\
\text { area of bus stop }\end{array}$ & Rate of flow (ped/min/m) & 51 & 47 \\
\hline $\begin{array}{c}\text { Reduce the number of } \\
\text { Bollard }\end{array}$ & Velocity $(\mathrm{m} / \mathrm{sec})$ & 0.76 & 1.14 \\
& Level Of Service & $\mathrm{E}$ & $\mathrm{D}$ \\
\hline $\begin{array}{c}\text { Expand width of } \\
\text { sidewalk }\end{array}$ & Duration & 53 & 42 \\
& Level Of Service & 0.94 & 1.09 \\
& Velocity(m/sec) & $\mathrm{E}$ & $\mathrm{D}$ \\
\hline
\end{tabular}

\section{Scenario 1: Mark on Sidewalk at Area of Bus Stop}

When we supply street furniture at the site as marking on bus stop area, overall level of service at the site seems to increase from $\mathrm{E}$ to $\mathrm{D}$ by analyzing rate of flow and velocity. Marking on sidewalk is set to reduce conflict between bus passengers and pedestrians. So, through mark on bus waiting area as street furniture, pedestrians and passengers could recognize the bus waiting area in advance. Therefore, conflict between pedestrians and passengers reduced and velocity of pedestrian was increased.

\section{Scenario 2: Reduce the Number of Bollard from 14 to 8}

When we supply street furniture at the site as reducing the number of bollard, overall level of service at the site seems to increase from $E$ to $D$ by analyzing duration and velocity. Existing bollard was restricting the movement of pedestrians. Pedestrians should act to avoid conflicts with bollard. In the process, velocity of pedestrians reduced and duration was increased. Therefore, we intended to minimize conflict by reducing the number of bollard. 


\section{Scenario 3: Expand Width of Sidewalk from 2.4m to 2.8m}

When we supply street furniture at the site as reducing the number of bollard, overall level of service at the site seems to increase from $\mathrm{D}$ to $\mathrm{D}$ by analyzing duration and velocity. The roles of expanding width of sidewalk are to decrease the collision between people moving to each direction, and to increase their walking speed at congested conditions. But, result of this analysis is analyzed that the width of the sidewalk affects small impact to pedestrians.

\subsection{Result of Simulation}

Existing model couldn't reflect the characteristics of pedestrians for the specific site. In this study, we developed a model that reflects the characteristics of pedestrians. We simulated situation that the level of service according to apply pedestrian facilities by the developed CA model. The model is allows to represent realistic characteristics such as a group moving behavior and a diagonal overtaking behavior. Though this model, we analyzed the effect of each street furniture. After selecting the site, the appropriate street furniture was selected in the site. The purpose of the selected street furniture is that maximizing the pedestrian space and eliminating possible factors that cause conflict. The effect of each street furniture could be analyzed by CA model that could reflect the characteristics of pedestrians. Developed CA model accurately analyze the effect of street furniture by reforming measurement of effectiveness.

\section{Conclusion}

City of Seoul is giving increasingly attention on pedestrian facilities in order to develop toward sustainable transport systems for pedestrians. The need for proper measurement of effectiveness of street furniture for pedestrian is now a key policy requirement to be evaluated. But, because the existing pedestrian models couldn't prove relationships between street furniture and movement of pedestrians, it couldn't reflect movement characteristics of pedestrians. In other words, the effect of supplying street furniture could not distinguish clearly. Therefore, it is important to measure the effectiveness of the pedestrian furniture in terms of its interaction with pedestrian movements. In this study, one site of the classified as low level of service is selected as the site to be get the street furniture and aims to analyze the effect of street furniture. Before supplying the street furniture, characteristics of pedestrian movement was investigated by video camera. Result of survey, pedestrian represent group moving behavior and a diagonal overtaking behavior.

To reflect these characteristics, we have developed the pedestrian simulation model based on cellular automata techniques. This model has a flexibility to measure the effectiveness of pedestrian street furniture in terms of level of service index based on its interaction with pedestrian movements. We have experimented how to evaluate the effectiveness of different types of furniture, which can reduce the conflict pedestrian movements in some highly congested areas. This study has simulated the pedestrian's pattern by the developed cellular automata model. The model is able to represent realistic characteristics such as a group moving behavior and a diagonal overtaking behavior. Specifically, more flexibility is given to the movement of pedestrians by developing the diagonal lane change.

We apply to (1) Mark on sidewalk at area of bus stop (2) Reduce the number of Bollard (3) Expand width of sidewalk at the site as alternatives for pedestrians. The result of these scenarios is analyzed to improve the measurement of effectiveness.

Through this study, we determined that the developed model would be appropriate to analyze the effect of supply the other street furniture. In addition, site similar to the presented problem would require street furniture that presented in this study in order to increase level of service. 
Furthermore, through developed model in this study, we analyze the effectiveness of various street furniture and derive typical results such as unit requirement for each of street furniture.

\section{Acknowledgment}

This work was supported by Architecture \& Urban Development Research Program in the Ministry of Land, Infrastructure and Transport in Korea [Grant number 16CTAPC116368-01].

\section{References}

[1] C. Adami, "Introduction to artificial life", Springer Science \& Business Media, vol. 1, (1998).

[2] P. Bak, "How nature works: the science of self-organized criticality", Nature, vol. 383. no. 6603, (1996), pp.772-773.

[3] C. Burstedde, K. Klauck, A. Schadschneider and J. Zittartz, "Simulation of pedestrian dynamics using a two-dimensional cellular automaton", Physica A: Statistical Mechanics and its Applications, vol. 295, no. 3-4, (2001), pp. 507-525.

[4] B. Chopard and M. Droz, "Cellular automata modeling of physical systems", Collection Aléa-Saclay: Monographs and Texts in Statistical Physics, (1998).

[5] J. J. Fruin, "Pedestrian planning and design, Metropolitan association of urban designers and environmental planners", Inc., New York, (1971).

[6] A. Kirchner and A. Schadschneider, "Simulation of evacuation processes using a bionics-inspired cellular automaton model for pedestrian dynamics", Physica A: statistical mechanics and its applications, vol. 312, no. 1-2, (2002), pp. 260-276.

[7] H. K. Lee, R. Barlovic, M. Schreckenberg and D. Kim, "Mechanical restriction versus human overreaction triggering congested traffic states", Physical review letters, vol. 92, no. 23, 238702, (2004).

[8] S. Lee, S. Lee and S. Lee, "Measuring effectiveness of pedestrian facilities using a pedestrian simulation model", In International Conference on Computational Science and Its Applications, Springer, Berlin, Heidelberg, (2009), pp. 413-425.

[9] S. Lee, "Analysis of pedestrian level of service in Seoul", Seoul Development Institute, (2011).

[10] S. Levy, "Artificial life: the quest for a new creation", Random House Inc., (1992).

[11] G. G. Løvås, "Modeling and simulation of pedestrian traffic flow", Transportation Research Part B: Methodological, vol. 28, no. 6, (1994), pp. 429-443.

[12] J. Matsukidaira and K. Nishinari, "Euler-Lagrange correspondence of cellular automaton for traffic-flow models", Physical review letters, vol. 90, no. 8, 088701, (2003).

[13] M. Muramatsu, T. Irie and T. Nagatani, "Jamming transition in pedestrian counter flow", Physica A: Statistical Mechanics and its Applications, vol. 267, no. 3-4, (1999), pp. 487-498.

[14] Y. Tajima, K. Takimoto and T. Nagatani, "Scaling of pedestrian channel flow with a bottleneck", Physica A: Statistical Mechanics and its Applications, vol. 294, no. 1-2, (2001), pp. 257-268.

[15] K. Takimoto and T. Nagatani, "Spatio-temporal distribution of escape time in evacuation process", Physica A: Statistical Mechanics and its Applications, vol. 320, (2003), pp. 611-621. 